\title{
Gluten-free diet does not appear to induce endoscopic remission of eosinophilic esophagitis in children with coexistent celiac disease
}

\author{
Joseph R Abraham BSc, Rabin Persad MD FRCPC, \\ Justine M Turner MD FRACP PhD, Hien Q Huynh MD FRACP
}

\begin{abstract}
JR Abraham, R Persad, JM Turner, HQ Huynh. Gluten-free diet does not appear to induce endoscopic remission of eosinophilic esophagitis in children with coexistent celiac disease. Can J Gastroenterol 2012;26(8):521-524.
\end{abstract}

BACKGROUND: Celiac disease and eosinophilic esophagitis are usually considered to be separate gastrointestinal diseases; however, it appears that they may coexist more often than would be expected. It is unknown whether eosinophilic esophagitis in patients with celiac disease responds to a gluten-free diet.

OBJEVTIVES: To examine the clinical, endoscopic and histological features of children with both conditions to evaluate whether eosinophilic esophagitis responds to a gluten-free diet.

METHODS: From January 1, 2009, to June 30, 2011, the medical records of children $<18$ years of age diagnosed with eosinophilic esophagitis and/or celiac disease were reviewed. Patients with clinical, endoscopic and histological diagnoses of both diseases were identified and included. These findings were analyzed, as were laboratory results, treatment and follow-up.

RESULTS: During the study period, there were 206 celiac disease patients, 86 eosinophilic esophagitis patients and nine $(4.4 \%$ of total celiac) patients with both diagnoses. Gluten-free diet was the primary treatment for both conditions in seven of nine $(78 \%)$ cases. In six of these seven $(86 \%)$ patients, no endoscopic or histological improvement of eosinophilic esophagitis was observed, while in one patient, histological remission of esophageal eosinophilia occurred while on a gluten-free diet.

CONCLUSION: The prevalence of eosinophilic esophagitis in patients with celiac disease was $4.4 \%$, confirming a higher than expected prevalence of eosinophilic esophagitis compared with the general population. In patients with celiac disease, a gluten-free diet did not appear to induce remission of coexistent endoscopic and histological features of eosinophilic esophagitis.

Key Words: Case series; Celiac disease; Eosinophilic esophagitis; Glutenfree diet

lthough completely distinct gastrointestinal (GI) entities, celiac Adisease (CD) and eosinophilic esophagitis (EoE) have been found to coexist in a number of young patients (1). It is possible that incidence and prevalence rates of both conditions may be increasing due to increased awareness and improved detection alone; it is also plausible that these two diseases are etiopathologically linked. The exact nature of this association has yet to be identified and further investigation may yield insights into the etiologies of each condition.

$\mathrm{CD}$ is the most common autoimmune GI disorder, with a prevalence of $0.3 \%$ to $1.3 \%(2,3)$. Patients can present with typical GI symptoms, or have atypical or no symptoms following screening $(4,5)$. Unlike EoE, CD has a strong genetic component, with the most common reason for screening being a first-degree relative with CD (6). In
Le régime sans gluten ne semble pas induire de rémission endoscopique de l'œsophagite à éosinophiles chez les enfants également atteints d'une maladie coliaque

HISTORIQUE : La maladie cœliaque et l'œsophagite à éosinophiles sont généralement considérées comme des maladies gastro-intestinales distinctes. Cependant, il semble qu'elles coexisteraient plus souvent qu'on ne le croit. On ne sait pas si, chez les patients atteints d'une maladie cœliaque, l'œsophagite à éosinophiles répond à un traitement sans gluten.

OBJECTIFS : Examiner les caractéristiques cliniques, endoscopiques et histologiques des enfants ayant les deux maladies pour évaluer si l'œsophagite à éosinophiles répond à un régime sans gluten.

MÉTHODOLOGIE : Du $1^{\text {er }}$ janvier au 30 juin 2011, les chercheurs ont analysé les dossiers médicaux d'enfants de moins de 18 ans ayant reçu un diagnostic d'œsophagite à éosinophiles, de maladie cœliaque ou des deux maladies. Ils ont repéré et inclus les patients ayant un diagnostic clinique, endoscopique et histologique des deux maladies. Ils ont analysé ces observations, de même que les résultats de laboratoire, le traitement et le suivi.

RÉSULTATS : Pendant la période de l'étude, les chercheurs ont recensé 206 patients atteints d'une maladie coliaque, 86 patients atteints d'une œsophagite à éosinophiles et neuf patients ( $4,4 \%$ du total des patients atteints d'une maladie coliaque) ayant les deux diagnostics. Dans sept des neuf cas (78\%), le régime sans gluten était le traitement primaire des deux maladies. Chez six de ces sept patients ( $86 \%$ ), on n'observait aucune amélioration endoscopique ou histologique de l'œsophagite à éosinophiles, tandis que chez un patient, on a observé une rémission histologique de l'œsophagite à éosinophiles pendant le régime sans gluten. CONCLUSION : La prévalence d'œsophagite à éosinophiles chez les patients atteints d'une maladie coliaque s'élevait à $4,4 \%$, ce qui confirme une prévalence plus élevée que prévu de l'œsophagite à éosinophiles par rapport à la population générale. Chez les patients atteints d'une maladie cœliaque, un régime sans gluten ne semblait pas induire de rémission des caractéristiques endoscopiques et histologiques coexistant avec l'œsophagite à éosinophiles.

addition, there is a strong association between CD and other autoimmune diseases including type 1 diabetes and autoimmune thyroiditis (7). The prevalence of EoE was recently estimated to be 4.3 per 10,000 of the pediatric population over a 19 -year span (8). EoE is characterized as a clinicopathological disease, with diagnosis based on endoscopic and histological findings in combination with typical symptoms such as dysphagia and food impaction (9).

While there have been recent studies suggesting these two GI diseases occur together with greater frequency than expected in the general pediatric population, no consensus has been reached regarding treatment, given their simultaneous occurrence. In particular, the role of a gluten-free diet (GFD), necessary for resolution of endoscopic and histological findings of $\mathrm{CD}$, in treating coexistent EoE is controversial.

Division of Pediatric Gastroenterology and Nutrition, Department of Pediatrics, Stollery Children's Hospital, University of Alberta, Edmonton, Alberta

Correspondence: Dr Hien Q Huynh, Department of Pediatrics, Division of Gastroenterology and Nutrition, University of Alberta, Room 9219,

11402 University Avenue, Edmonton, Alberta T6G 2J3. Telephone 780-407-3339, fax 780-407-35, e-mail hien.huynh@ualberta.ca

Received for publication August 3, 2011. Accepted December 14, 2011 
Some studies have found little resolution of esophageal eosinophilia when patients are on a GFD, despite the expected improvement in duodenal histology. However, one study contradicted these findings (10), reporting patients with both diseases, but predominantly symptoms of EoE, improved both clinically and histologically after commencing a GFD. We aimed to determine the number of children with both EoE and CD diagnosed at our institution and to assess whether the EoE component responded to a GFD.

\section{METHODS}

The present study was conducted in the Department of Pediatric Gastroenterology at the Stollery Children's Hospital, University of Alberta (Edmonton, Alberta). Children with histologically confirmed CD between January 2009 and June 2011 were identified by searching all endoscopy and histology reports for this period and cross-referencing with the Celiac Clinic database. A diagnosis of CD required confirmation of a Marsh 2 or 3 lesion on duodenal histology and subsequent histological response after treatment with a GFD. Cases were also identified and confirmed through the EoE Clinic database. The pediatric gastroenterology service at the institution and these two specialty clinics service the entire pediatric population of Northern Alberta. Two primary gastroenterologists manage each subspecialty clinic.

The EoE database includes signs found in the esophagus on endoscopy such as linear furrowing, concentric esophageal rings, white exudates, narrowing of esophagus, loss of vascular pattern and a thickened esophagus. Histologically, EoE presents with mucosal eosinophilia, basal zone hyperplasia, intraepithelial eosinophils and a high number of eosinophils per high-power field (HPF) in both proximal and distal parts of the esophagus (9). While the required number of eosinophils for diagnosis has varied, based on histological criteria, the Stollery Children's Hospital defines a diagnosis of EoE when $>15$ eospinophils per HPF are present. Due to the nature of the study, it should be noted that the pathologist reviewing these cases was not blinded. Identified cases with esophageal biopsies confirming EoE and diagnosed with $\mathrm{CD}$ had their records reviewed and details compiled, including demographics, symptoms and findings (both endoscopic and histological), and treatment and response.

\section{RESULTS}

Between January 2009 and June 2011, 206 patients were diagnosed with $\mathrm{CD}$ and nine presented with concomitant EoE, a prevalence of approximately $4.4 \%$. Eight patients had an initial Marsh score of either 3B or 3A, while one patient had a Marsh score of 2. Clinical features of these patients are summarized in Table 1. Over the same period, 86 patients were diagnosed with EoE.

In seven of these cases, the indication for endoscopy was to confirm CD using antitransglutaminase level of $>7$ units $/ \mathrm{mL}$. All but one of the patients had typical symptoms of $\mathrm{CD}$ and one was asymptomatic. Symptoms of dysphagia were observed in three of these patients. Two patients (patients 4 and 5) had no symptoms that could be compatible with EoE and had only histological features of EoE.

In the two remaining cases, the indication for endoscopy was dysphagia.

As shown in Table 1, endoscopic features of EoE, such as vertical furrows, white exudate and loss of vascular pattern in the esophagus, were found in seven of the nine cases. On esophageal biopsy, basal cell hyperplasia and intraepithelial eosinophils of $>20$ eosinophils per HPF were found in eight of nine patients. Patient 1 presented with typical EoE symptoms and endoscopic features, and had an initial esophageal eosinophil count of 6 per HPF. However, this increased to 48 per HPF on the second scope, thus confirming EoE.

In seven cases, the only treatment initiated, after initial diagnosis of $\mathrm{CD}$ and EoE was simultaneously made, was a GFD. The mean duration of GFD before a repeat endoscopy for EoE in these seven pateints was five months (median and mode, six months each). One patient was treated with a combination of GFD and proton pump inhibitor (PPI) (three months before repeat endoscopy). The remaining patient was treated with fluticasone initially because CD was only diagnosed on the repeat endoscopy after two months. All patients, except patient 5 , reported compliance with a GFD, supported by a decrease in antitransglutaminase level or normalization of the duodenal biopsy at repeat endoscopy. In the case of patient 5 , both endoscopic and histological features of $\mathrm{CD}$ and $\mathrm{EoE}$ did not resolve. Only one patient (patient 4) experienced complete histological resolution of esophageal eosinophilia on GFD alone. All other patients with EoE and CD treated with a GFD alone failed to respond to the diet and required EoE treatment. One patient treated with GFD and a PPI (patient 8) experienced resolution of $\mathrm{CD}$, but experienced persistent EoE endoscopic changes. Although there was a decrease in peak eosinophil count from 22 eosinophils per HPF to 0 eosinophils per HPF in this case, there was worsening of symptoms and endoscopic hallmarks of EoE. The remaining patient (patient 9) was treated with a PPI before the first diagnostic scope and fluticasone after the diagnosis of EoE. Although this patient experienced complete endoscopic and histological resolution of EoE at follow-up endoscopy, this patient was subsequently found to have CD. Because GFD was not initiated when both conditions were present, a determination of whether this patient's EoE would respond to a GFD was not possible.

\section{DISCUSSION}

In the present study, we observed a $4.4 \%$ prevalence of EoE in children with CD. Two articles, both from Australia, reported a similar prevalence. Ooi et al (1) reported $3.2 \%$ of $221 \mathrm{CD}$ patients also had EoE, and Leslie et al (11) reported EoE in approximately 4\% of $250 \mathrm{CD}$ patients. Although prevalence rates of EoE appear to be increasing in Western countries, it is not clear whether differences in prevalence rates are due solely to different detection rates in various countries. In 2003, the prevalence of EoE in Hamilton County, Ohio (USA) was reported to be 43 per 100,000 by Noel et al (8), representing at least $0.04 \%$ of the pediatric population. The same study showed an increase over three years from 9.9 per 100,000 to 43 per 100,000. In Western Australia, the prevalence increased from approximately 5.0 per 100,000 in 1995 to 8.9 per 100,000 in 2004 (11).

As mentioned previously, CD is prevalent in approximately $0.3 \%$ to $1.3 \%$ of the pediatric population $(2,3)$. Given an estimated population prevalence of CD of $1 \%$ and EoE of $0.04 \%$ (10), the prevalence of patients having EoE and CD being 4.4\% of the CD patients does appear to be higher than expected. A recent study conducted at the Stollery Children's Hospital (12) found an 11-fold increase in the diagnoses of $\mathrm{CD}$ over a four-year period, suggesting that increased prevalence rates could very well be due to an increase in detection rates. Nonetheless, this association between the two diseases warrants far more consideration because it may shed light on the pathogenesis of each condition. EoE is an immunoallergic disease and, specifically, the pathogenesis is comprised of a $\mathrm{T}$ helper cell (Th) 2-mediated immune response, which is usually exacerbated by exposure to dietary allergens that in turn cause infiltration by $\mathrm{T}$ lymphocytes, eosinophils and mast cells in the esophageal mucosa (13). CD, on the other hand, is a Th1-mediated autoimmune disease that, in genetically susceptible individuals, is initiated by ingestion of gluten-containing foods (14). It would normally be assumed that different immunologically mediated diseases would have little in common, but population studies show just the opposite, with Th1-mediated autoimmune and Th2-mediated atopic diseases sharing common environmental risk factors, increasing the chances that either response is triggered (15). It is, therefore, entirely plausible that the antigenic response leading to small bowel mucosal disease in CD initiates a coupled immune response in the esophageal mucosa leading to eosinophil infiltration. Eliminating one antigen may resolve one disease, but not necessarily the other, which may continue to respond to other antigens.

As shown in the present study, a GFD does not appear to induce disease remission in both diseases. With the exception of patient 4, no patient experienced complete remission of EoE symptoms, endoscopy or histology findings after initial treatment with GFD, as shown in 
TABLE 1

Clinical, histological and endoscopic findings in children with both celiac disease (CD) and eosinophilic esophagitis (EoE)

\begin{tabular}{|c|c|c|c|c|}
\hline Patient & $\begin{array}{c}\text { Age, } \\
\text { years/sex }\end{array}$ & Symptoms & $\begin{array}{l}\text { Indication for } \\
\text { endoscopy }\end{array}$ & $\begin{array}{c}\text { First endoscopy and } \\
\text { histology }\end{array}$ \\
\hline 1 & $13 /$ male & $\begin{array}{l}\text { Dysphagia, } \\
\text { impaction, choking } \\
\text { on food, abdominal } \\
\text { pain, vomiting, } \\
\text { slow eater, } \\
\text { excessive chewing, } \\
\text { and food refusal }\end{array}$ & $\begin{array}{l}\text { Confirmed EoE. } \\
\text { CD found } \\
\text { incidentally, } \\
\text { ATTG } 117 \mathrm{U} / \mathrm{mL}\end{array}$ & $\begin{array}{l}\text { White exudates and } \\
\text { loss of vascular } \\
\text { pattern. Mild BCH } \\
\text { and } 6 \text { Eos/HPF in } \\
\text { esophagus. Marsh } \\
\text { Score of } 3 \mathrm{~A}\end{array}$ \\
\hline 2 & 10/male & $\begin{array}{l}\text { Family history of CD. } \\
\text { Asymptomatic for } \\
\text { CD. Dysphagia } \\
\text { noted on review }\end{array}$ & $\begin{array}{l}\text { Confirmed CD, } \\
\text { ATTG } 220 \mathrm{U} / \mathrm{mL}\end{array}$ & $\begin{array}{l}\text { White exudates and } \\
\text { vertical furrows. BCH } \\
\text { and } 33 \text { Eos/HPF in } \\
\text { esophagus. Marsh } \\
\text { Score of } 3 \mathrm{~A}\end{array}$ \\
\hline
\end{tabular}

3

8/female Abdominal pain and
food refusal, iron
deficiency, family
history of $C D$

Confirmed CD, Loss of vascular pat-

ATTG $310 \mathrm{U} / \mathrm{mL} \quad$ tern, vertical furrows and white exudates. $\mathrm{BCH}$ and 20 Eos/ HPF in esophagus. Marsh score of $3 \mathrm{~B}$ 12/male Poor growth

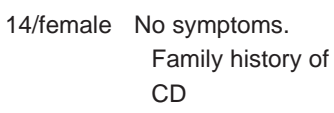

6 8/female Nocturnal diarrhea, constipation, weight loss and Family history of CD

$8^{\star}$ 15/female Abdominal pain,
bloating and slow
eater abdominal pain.
Confirmed CD, Normal endoscopy. ATTG $17 \mathrm{U} / \mathrm{mL} \quad \mathrm{BCH}$ and 27 Eos/HPF in esophagus. Marsh score $3 A$

Confirmed CD, Normal endoscopy. ATTG $280 \mathrm{U} / \mathrm{mL} \quad \mathrm{BCH}$ and 54 Eos/HPF in esophagus. Marsh score 3B

Confirmed $C D$, Vertical furrows and ATTG $43 \mathrm{U} / \mathrm{mL} \quad$ white exudates with duodenal edema. $\mathrm{BCH}$ and 50 Eos/HPF in esophagus. Marsh score 3B

Confirm CD, Loss of vascular Immunoglobulin A pattern, white deficient exudates. $\mathrm{BCH}$, 36 Eos/HPF in esophagus. Marsh score 2

Confirm CD,
ATTG $20 \mathrm{U} / \mathrm{mL}$

Vertical furrows and white exudates. $\mathrm{BCH}$, 22 Eos/HPF in esophagus. Marsh score $3 \mathrm{~A}$

Treatment

Endoscopy/histology/general
duodenal biopsy. Esophagea hypereosinophilia and endoscopic changes remain (48 Eos/HPF)

$\begin{array}{ccc}\text { GFD } & \text { ATTG } 12 \text { units/mL and normal } & \text { Endoscopy normalizes } \\ \text { duodenal biopsy. Esophageal } & \text { under fluticasone } \\ \text { hypereosinophilia and } & \text { (0 Eos/HPF) }\end{array}$
Endoscopy/histology after EoE treatment Endoscopy normalizes under fluticasone (0 Eos/HPF)

$$
\text { (48 EOS/HPF) }
$$

GFD Minor residual villous atrophy and Repeat endoscopy intraepithelial lymphocytosis in required for fluticasone bulb biopsy only. Esophageal hypereosinophilia and endoscopic changes remain (40 Eos/HPF). Repeat ATTG required

GFD ATTG $9.2 \mathrm{U} / \mathrm{mL}$ and normal duodenal biopsy. Esophageal hypereosinophilia, $\mathrm{BCH}$ and endoscopic changes remain (50 Eos/HPF) treatment

\section{Endoscopy normalizes under fluticasone (0 Eos/HPF)}

GFD Improvement in inflammation of Not on EoE treatment duodenum. Complete resolution of esophageal hypereosinophilia (0 Eos/HPF) and $\mathrm{BCH}$

GFD Noncompliant on GFD and Marsh Repeat endoscopy score 3A. Endoscopic with vertical furrows and loss of vascular pattern (>30 Eos/HPF)

GFD ATTG of $1.2 \mathrm{U} / \mathrm{mL}$ and normal duodenal biopsy. Esophageal hypereosinophilia and endoscopic changes remain (50 Eos/HPF). Still has abdominal pain

GFD Normal duodenal biopsy. Persistent EoE changes (45 Eos/HPF). Repeat ATTG required

\section{GFD and Normal duodenal biopsy. PPI Resolution of esophageal intraepithelial eosinophil} (0 Eos/HPF), yet $\mathrm{BCH}$ remains with persistent endoscopic changes without white exudates. Repeat ATTG required

Fluticasone CD disease detected during second endoscopy; therefore, repeat endoscopy required to determine effect of GFD. EoE resolved completely after initial treatment (0 Eos/HPF) required for fluticasone treatment

Endoscopy normalizes under fluticasone (18 Eos/HPF). Abdominal pain improves slightly

\section{Endoscopy normalizes (3 Eos/HPF) with budesonide}

Not on EoE treament Endoscopy normalizes
(0 Eos/HPF) with
fluticasone
Confirmed EoE. Loss of vascular CD found pattern, thickened second endoscopy, ATTG $920 \mathrm{U} / \mathrm{mL}$ after second concentric rings. $\mathrm{BCH}$ and 40 Eos/HPF in esophagus. Duodenum was not examined

${ }^{*}$ Combination gluten-free diet (GFD) and proton pump inhibitor (PPI) treatment; ${ }^{\dagger}$ EoE initial treatment, then GFD; ATTG Antitransglutaminase; BCH Basal cell hyperplasia; CD Celiac disease; Eos Eosinophils; HPF High-powered field 
Table 1. Instead, specific EoE treatment was required. In patients who initiated a GFD alone as therapy, our study showed that a GFD is of little benefit in patients with endoscopic and histological changes consistent with EoE. This is consistent with nearly all available current literature. Two previous studies demonstrated that patients exhibited resolution of duodenal histology, yet no resolution of the clinical, endoscopic or histological findings of their $\operatorname{EoE}(1,11)$. One exception to this is found in a study by Quaglietta et al (10), in which three of six patients with both $\mathrm{EoE}$ and $\mathrm{CD}$ experienced vast improvement of clinical and histological findings of EoE after treatment with a GFD, and in which nearly all six patients experienced improvement in clinical symptoms. However, none of these patients experienced histological remission in their esophagus post-GFD. The authors did not provide all patients' peak esophageal eosinophil counts pre- and post-GFD treatment. Hence, it is difficult for the authors to support their claim that GFD is, in fact, an effective treatment for EoE in patients with coexistent $\mathrm{CD}$. What can be taken from the study by Quaglietta et al (10), however, is that GFD, as shown in patient 4 of our study, can result in a decrease in the peak esophageal eosinophil count in CD patients with little other signs of EoE, apart from esophageal hypereosinophilia.

The present study was limited by its retrospective nature. One of the limitations stemming from this was that the pathologist reviewing the EoE cases was not blinded before and after GFD was initiated. Although this is an inherent problem of retrospective case series, the lack of blinding would probably not have a substantial effect on study results, given that clinically, most patients showed positive signs of EoE on endoscopy even after GFD, as shown in Table 1. However, to get a better understanding of the association between EoE and CD and the role of a GFD in their treatment, a prospective trial must be undertaken detailing clinical symptoms of EoE and gastroesophageal reflux before diagnosis, along with endoscopic and histological assessment of the esophagus before and after initiating a GFD. Our current data do not support the use of GFD in the treatment of EoE in patients with $\mathrm{CD}$. The present study cannot exclude the fact that there may be a subgroup of patients with CD and esophageal hypereosinophilia, without other manifestations of EoE, who do respond to a GFD.

FUNDING: Vessie Heckbert Memorial Summer Research Award.

\section{REFERENCES}

1. Ooi CY, Day AS, Jackson R, et al. Eosinophilic esophagitis in children with celiac disease. J Gastroenterol Hepatol 2008;23:1144-8.

2. Rodrigues AF, Jenkins HR. Investigation and management of coeliac disease. Arch Dis Child 2008;93:251-4.

3. Lurz E, Scheidegger U, Spalinger J, et al. Clinical presentation of celiac disease and the diagnostic accuracy of serologic markers in children. Eur J Pediatr 2009;168:839-45.

4. Rutz R, Ritzler E, Fierz W, et al. Prevalence of asymptomatic celiac disease in adolescents of eastern Switzerland. Swiss Med Wkly 2002;132:43-7.

5. Dewar DH, Ciclitira PJ. Clinical features and diagnosis of celiac disease. Gastroenterology 2005;128:S19-24.

6. Hogberg L, Falth-Magnusson K, Grodzinsky E, et al. Familial prevalence of coeliac disease: A twenty-year follow-up study. Scand J Gastroenterol 2003;38:61-5.

7. Madani S, Kamat D. Clinical guidelines for celiac disease in children: What does it mean to the pediatrician/family practitioner? Clin Pediatr (Phila) 2006;45:213-9.

8. Noel RJ, Putnam PE, Rothenberg ME. Eosinophilic esophagitis. N Engl J Med 2004;351:940-1.

9. Liacouras CA, Furuta GT, Hirano I, et al. Eosinophilic esophagitis: Updated consensus recommendations for children and adults. J Allergy Clin Immunol 2011;128:3-20:e6.

10. Quaglietta L, Coccorullo P, Miele E, et al. Eosinophilic oesophagitis and coeliac disease: Is there an association? Aliment Pharmacol Ther 2007;26:487-93.

11. Leslie C, Mews C, Charles A, et al. Celiac disease and eosinophilic esophagitis: A true association. J Pediatr Gastroenterol Nutr 2010;50:397-9.

12. Rajani $S$, Huynh $H Q$, Turner J. The changing frequency of celiac disease diagnosed at the Stollery Children's Hospital. Can J Gastroenterol 2010;24:109-12.

13. Lucendo AJ, Lucendo B. An update on the immunopathogenesis of eosinophilic esophagitis. Expert Rev Gastroenterol Hepatol 2010;4:141-8.

14. Lucendo AJ, Arias A, Perez-Martinez I, et al. Adult patients with eosinophilic esophagitis do not show an increased frequency of the HLA-DQ2/DQ8 genotypes predisposing to celiac disease. Dig Dis Sci 2011;56:1107-11.

15. Simpson CR, Anderson WJ, Helms PJ, et al. Coincidence of immune-mediated diseases driven by Th1 and Th2 subsets suggests a common aetiology. A population-based study using computerized general practice data. Clin Exp Allergy 2002;32:37-42. 


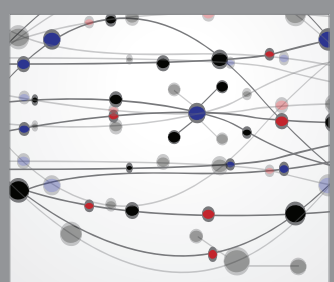

The Scientific World Journal
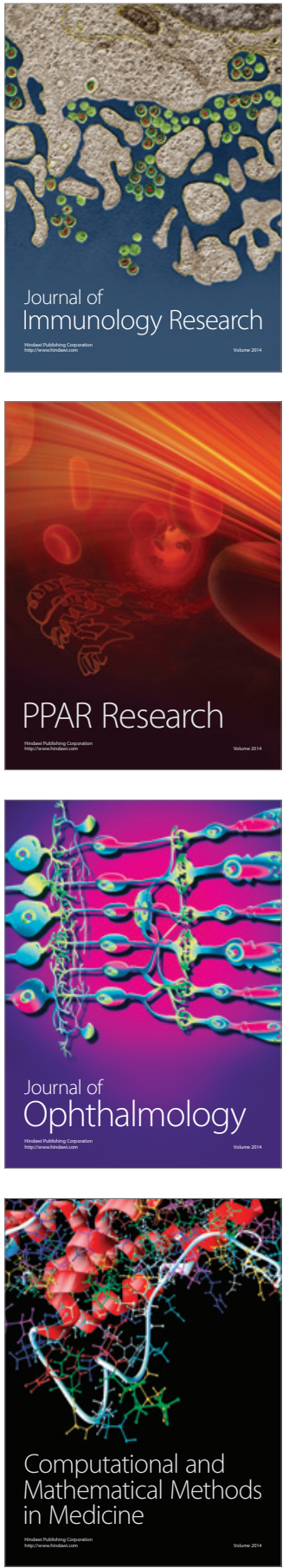

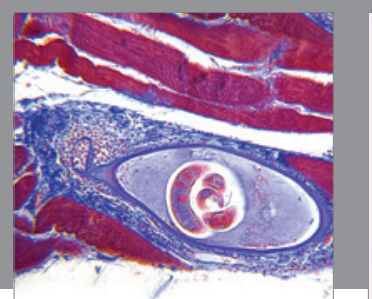

Gastroenterology Research and Practice

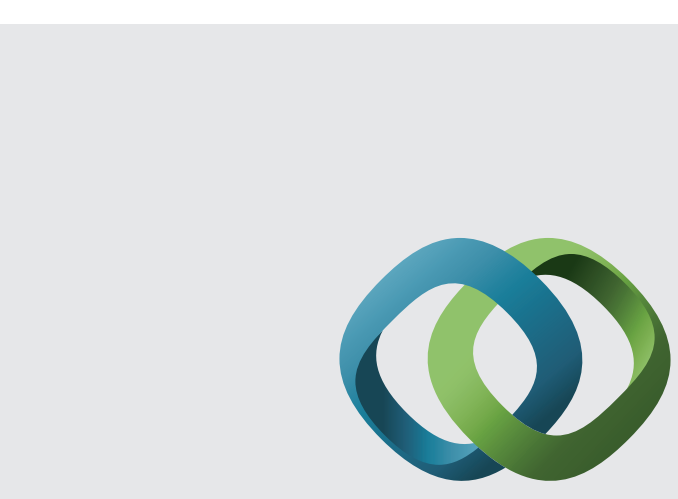

\section{Hindawi}

Submit your manuscripts at

http://www.hindawi.com
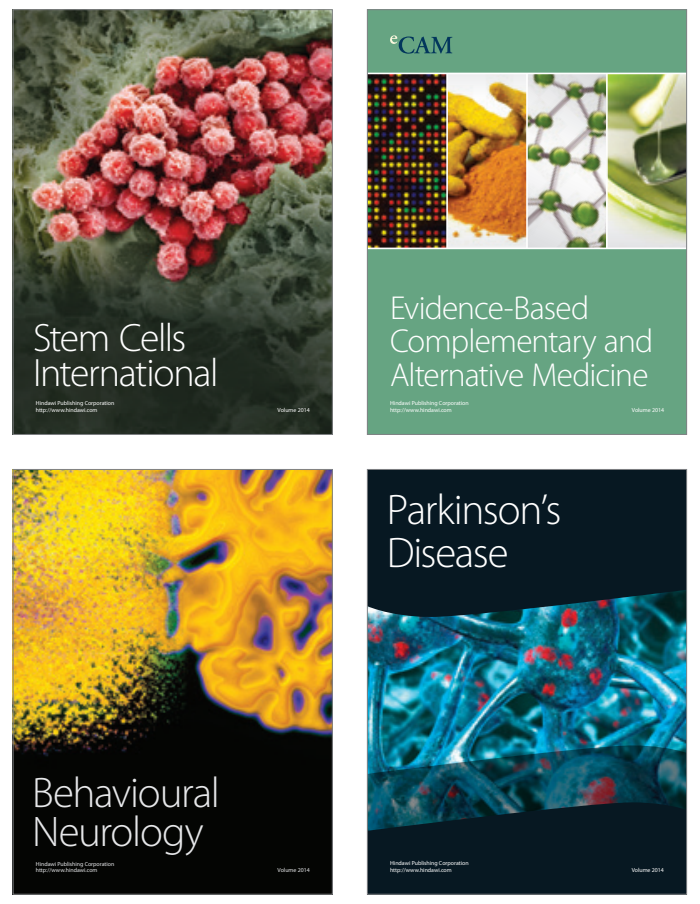
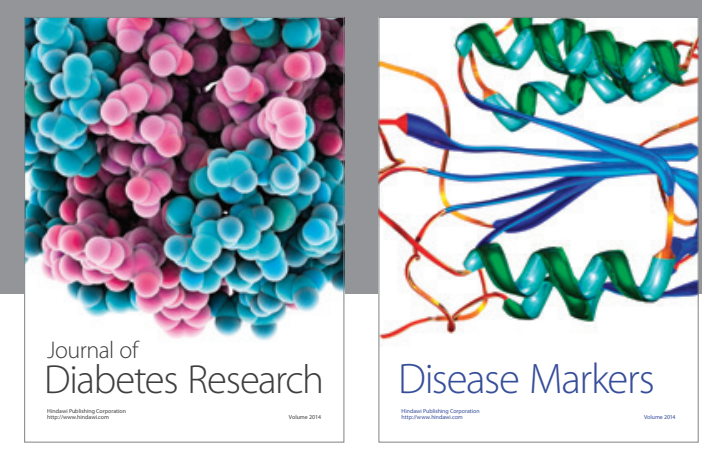

Disease Markers
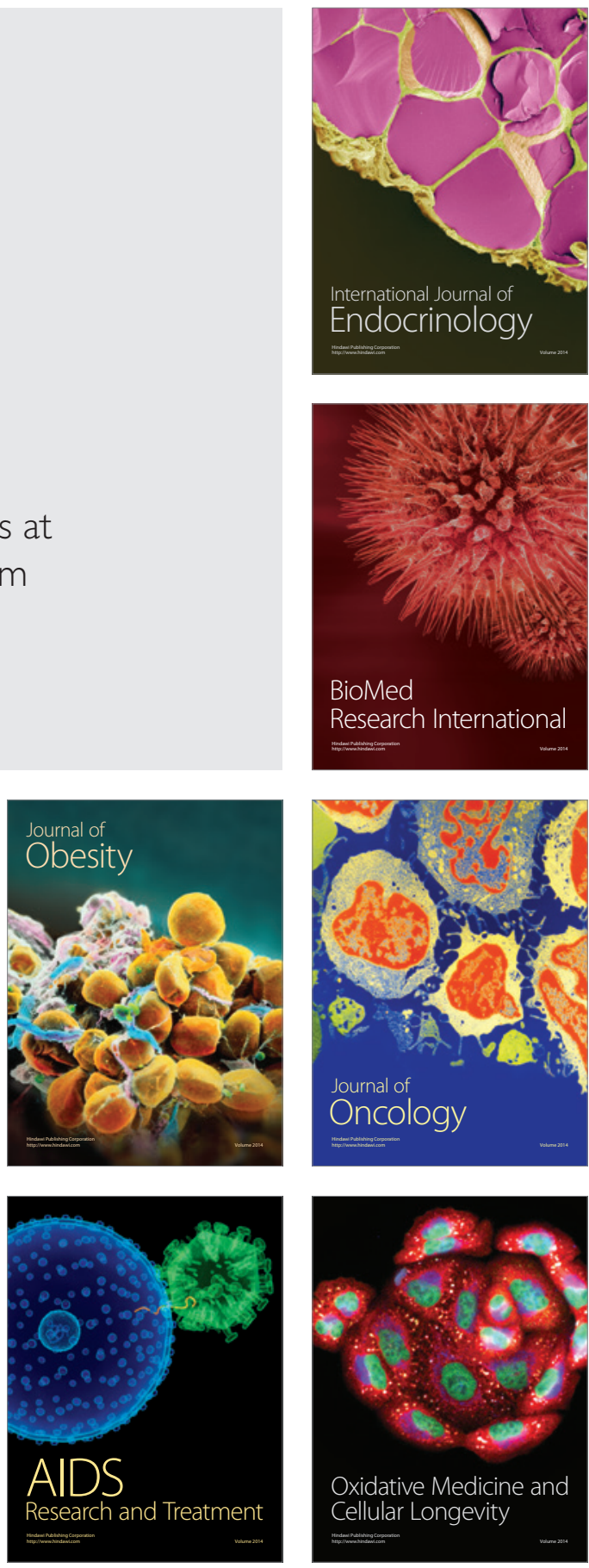